\title{
Evaluation of Thermodynamic Properties of Alkaline Borogermanates and Germanosilicates Using the Regression Analysis Method
}

\author{
M. V. Shtenberg ${ }^{1 *}$, V. A. Bychinsky ${ }^{2}$, A. A. Tupitsyn ${ }^{3}$, O. N. Koroleva ${ }^{1}$ \\ ${ }^{1}$ Institute of Mineralogy SU FRC MG UB RAS, Miass, Russia \\ ${ }^{2}$ Vinogradov Institute of Geochemistry SB RAS, Irkutsk, Russia \\ ${ }^{3}$ Irkutsk State Transport University, Irkutsk, Russia \\ E-mail: ${ }^{1}$ shtenberg@mineralogy.ru
}

Received 9 July 2020, Revised 28 October 2020, Accepted 21 November 2020

\begin{abstract}
A novel method for calculating the thermodynamic properties of ternary oxides using borogermanates and germanosilicates as examples is proposed. Using regression coefficients obtained for germanates, borates and silicates, the heat capacity, formation enthalpy, entropy and Gibbs free energy of alkaline borogermanates and germanosilicates were calculated. The obtained enthalpy of formation values are in good agreement with experimental data. In the regression equation, the alkaline oxide thermodynamic potential coefficients were found to depend on the class of compound.
\end{abstract}

\section{Keywords: thermodynamic potentials; borogermanate; germanosilicate; regression analysis; evaluation.}

\section{Introduction}

Compounds containing network formers are widely used in various industries, in particular for the production of nonlinear optical laser systems, phosphors, light emitting diodes and microporous materials. Of great interest in such industries are borogermanates and germanosilicates [1-12]. Materials having specified physicochemical properties can be obtained by entering into the structure of crystals and glasses capable of forming their own sublattices in various ratios of $\mathrm{Ge}, \mathrm{B}$, and $\mathrm{Si}$ atoms.

Information on the stability and reactivity of molecules, which is a key factor for the synthesis of compounds, can be obtained via thermodynamic potentials. Nevertheless, there is currently little thermodynamic data on germanates. However, several studies on the high temperature heat capacity of rare earth germanates are extant [13-15]. These compounds are very promising in practical terms due to their luminescent properties. The thermodynamic properties of borogermanates are presented only in two studies [16, 17].

While obtaining experimental data through synthesis is too difficult or costly, empirical methods for calculating the thermodynamic properties can offer a good alternative. A number of methods for calculating heat capacity, entropy, Gibbs energy and standard enthalpy of formation are used in various industries. A review of empirical methods for calculating the heat capacity of oxide compounds is presented in [18]. According to the authors, the most effective method is the Neumann-Kopp rule (NKR), which relates the heat capacity of an $\mathrm{A}_{2 a} \mathrm{~B}_{3 b} \mathrm{O}_{x}$-type compound to the heat capacity of simple oxides $\mathrm{A}_{a} \mathrm{O}_{m}$ and $\mathrm{B}_{b} \mathrm{O}_{n}$ as follows:

$$
C_{p}{ }^{\circ}\left(\mathrm{A}_{2 a} \mathrm{~B}_{3 b} \mathrm{O}_{x}\right)=2 C_{p}{ }^{\circ}\left(\mathrm{A}_{a} \mathrm{O}_{m}\right)+3 C_{p}{ }^{\circ}\left(\mathrm{B}_{b} \mathrm{O}_{n}\right)
$$

The advantage of NKR is its versatility and high accuracy. However, in addition to heat capacity, physicochemical modelling requires information on other thermodynamic potentials, such as entropy, formation enthalpy and Gibbs energy, which cannot be obtained directly via NKR. As shown in our previous works [19, 20], the regression analysis method can be successfully used to calculate the heat capacity, entropy and enthalpy of formation, from which it is already possible to calculate the Gibbs energy. The advantage of regression analysis compared to NKR is that it can be used to work with a large number of initial experimental data, allowing the overall calculation error to be reduced. Conversely, the accuracy of NKR is largely due to the reliability of determining the specific heat capacity of the simple oxides that make up the compound.

The standard enthalpy of formation can be obtained by adding the reaction enthalpy $\left(\Delta \mathrm{H}^{\circ}\right)$ of the simple oxides combined into a double oxide to the sum of the standard enthalpies of formation of the simple oxides [21]. In this way, the reaction enthalpy can be estimated from the electronegativities of the component elements. This method allows the standard enthalpies of formation to be calculated to a reasonable degree of accuracy for most binary oxides.

The versatile method for approximating thermodynamic functions for solids proposed by Voronin works well with a small quantity of experimental data [26]. Subsequently, Uspenskaya [27] expanded the application of this method for estimating entropy with limited heat capacity temperature measurements.

The Thermodynamic Difference Rule (TDR) is used to evaluate the thermodynamic properties of hydrates [22-25]. Jenkins has shown that this rule, which can be effectively used in evaluating entropy, enthalpy of formation and Gibbs free energy, works well for many hydrates. Moreover, this rule can also be used to estimate the thermodynamic properties of anhydrous compounds in the presence of data on hydrates corresponding in composition.

It should be noted that classical reference databases such as [28-30], including the latest NIST-JANAF Internet publications, mainly contain thermodynamic data for binary 
oxides. More complex compounds, such as borogermanates and germanosilicates, are poorly studied; hence, empirical methods for calculating their thermodynamic properties are required. The primary aim of this work was the development of a method for calculating the thermodynamic properties of ternary systems using regression analysis.

\section{Methods}

The multiple regression equation for calculating the thermodynamic properties in general can be written as follows:

$$
y_{i}=\sum_{i=1}^{m} b_{j} x_{i j}
$$

where $y_{i}-$ is the value of the thermodynamic potential for the $i$-th basic component.

$b_{j}$ - multiple regression coefficients.

$x_{i j}-$ are molar fractions of oxides for the $i$-th basic component.

In matrix form, Eg. (1) is written as:

$Y=b X$,

$Y=\left(\begin{array}{c}\mathrm{y}_{1} \\ \mathrm{y}_{2} \\ \cdot \\ \mathrm{y}_{\mathrm{n}}\end{array}\right) ; \quad X=\left[\begin{array}{cccc}\mathrm{x}_{11} & \mathrm{x}_{12} & \cdot & \mathrm{x}_{1 \mathrm{~m}} \\ \mathrm{x}_{21} & \mathrm{x}_{22} & \cdot & \mathrm{x}_{2 \mathrm{~m}} \\ \cdot & \cdot & \cdot & \cdot \\ \mathrm{x}_{\mathrm{n} 1} & \mathrm{x}_{\mathrm{n} 2} & \cdot & \mathrm{x}_{\mathrm{nm}}\end{array}\right]$

The basic components consist of elements, oxides and ions of which the compound consists. In the case of oxide systems, the composition of the compounds is conveniently represented as oxides. It should be noted that errors in the experimental data on the thermodynamic characteristics of compounds are different for well- and poorly-studied compounds. In some cases, the error can vary by an order of magnitude. We take this into account in our calculations by introducing weighting factors equal to $1 / \sigma$, where $\sigma$ is the measurement error. Thus, in the regression analysis, the contribution of more accurate values is given a higher weighting, while the values with a large error are weighted lower. Then Eg. (1) will look as follows:

$$
\begin{aligned}
& y / \sigma=b_{1} x_{\mathrm{SiO}_{2}} / \sigma+b_{2} x_{\mathrm{B}_{2} \mathrm{O}_{3}} / \sigma+b_{3} x_{\mathrm{GeO}_{2}} / \sigma+ \\
& +b_{4} x_{\mathrm{Li}_{2} \mathrm{O}} / \sigma+b_{5} x_{\mathrm{Na}_{2} \mathrm{O}} / \sigma+b_{6} x_{\mathrm{K}_{2} \mathrm{O}} / \sigma,
\end{aligned}
$$

The final matrix for regression analysis is written as:

$$
Y=\left(\begin{array}{c}
\mathrm{y}_{1} / \sigma_{1} \\
\mathrm{y}_{2} / \sigma_{2} \\
\cdot \\
\mathrm{y}_{\mathrm{n}} / \sigma_{\mathrm{n}}
\end{array}\right) ; \quad X=\left[\begin{array}{cccc}
\mathrm{x}_{11} / \sigma_{1} & \mathrm{x}_{12} / \sigma_{1} & \cdot & \mathrm{x}_{1 \mathrm{~m}} / \sigma_{1} \\
\mathrm{x}_{21} / \sigma_{2} & \mathrm{x}_{22} / \sigma_{2} & \cdot & \mathrm{x}_{2 \mathrm{~m}} / \sigma_{2} \\
\cdot & \cdot & \cdot & \cdot \\
\mathrm{x}_{\mathrm{n} 1} / \sigma_{\mathrm{n}} & \mathrm{x}_{\mathrm{n} 2} / \sigma_{\mathrm{n}} & \cdot & \mathrm{x}_{\mathrm{nm}} / \sigma_{\mathrm{n}}
\end{array}\right]
$$

When analysing the correctness of the calculations and their coordination, the fact that the values of $b_{j}$ must have the same sign is taken into account. That is, each structural component makes the same contribution to the total value of the potential. The thermodynamic potentials for unknown compounds are calculated on the basis of the obtained dependencies.

\section{Results and Discussion \\ 3.1. Binary oxide compounds}

I. In order to assess the thermodynamic properties of borogermanates and germanosilicates, we previously obtained the dependencies of entropy, formation enthalpy and heat capacity on the composition for alkaline silicates, borates, and germanates [19, 20].

$S^{\circ}\left(x_{i j} \mathrm{Me}_{2} \mathrm{O} \cdot x_{i 1} \mathrm{SiO}_{2} ; 298.15 \mathrm{~K}\right)=43.153 \cdot x\left(\mathrm{SiO}_{2}\right)+$

$+38.366 \cdot x\left(\mathrm{Li}_{2} \mathrm{O}\right)+73.796 \cdot x\left(\mathrm{Na}_{2} \mathrm{O}\right)+$

$+103.426 \cdot x\left(\mathrm{~K}_{2} \mathrm{O}\right) \mathrm{J} \cdot \mathrm{K}^{-1} \cdot \mathrm{mol}^{-1}$.

$S^{\circ}\left(x_{i j} \mathrm{Me}_{2} \mathrm{O} \cdot x_{i 1} \mathrm{~B}_{2} \mathrm{O}_{3} ; 298.15 \mathrm{~K}\right)=43.311 \cdot x\left(\mathrm{~B}_{2} \mathrm{O}_{3}\right)+$

$+60.682 \cdot x\left(\mathrm{Li}_{2} \mathrm{O}\right)+102.978 \cdot x\left(\mathrm{Na}_{2} \mathrm{O}\right)+$

$+117.058 \cdot x\left(\mathrm{~K}_{2} \mathrm{O}\right) \mathrm{J} \cdot \mathrm{K}^{-1} \cdot \mathrm{mol}^{-1}$.

$S^{\circ}\left(x_{i j} \mathrm{Me}_{2} \mathrm{O} \cdot x_{i 1} \mathrm{GeO}_{2} ; 298.15 \mathrm{~K}\right)=48.657 \cdot x\left(\mathrm{GeO}_{2}\right)+$

$+44.603 \cdot x\left(\mathrm{Li}_{2} \mathrm{O}\right)+83.425 \cdot x\left(\mathrm{Na}_{2} \mathrm{O}\right)+$

$+117.202 \cdot x\left(\mathrm{~K}_{2} \mathrm{O}\right) \mathrm{J} \cdot \mathrm{K}^{-1} \cdot \mathrm{mol}^{-1}$.

Similar equations were also obtained for the standard enthalpy of formation from simple compounds:

$\Delta_{f} H^{\circ}\left(x_{i j} \mathrm{Me}_{2} \mathrm{O} \cdot x_{i 1} \mathrm{SiO}_{2} ; 298.15 \mathrm{~K}\right)=$

$=-919.788 \cdot x\left(\mathrm{SiO}_{2}\right)-720.705 \cdot x\left(\mathrm{Li}_{2} \mathrm{O}\right)-$

$-625.385 \cdot x\left(\mathrm{Na}_{2} \mathrm{O}\right)-650.962 \cdot x\left(\mathrm{~K}_{2} \mathrm{O}\right) \mathrm{kJ} \cdot \mathrm{mol}^{-1}$.

$\Delta_{f} H^{\circ}\left(x_{i j} \mathrm{Me}_{2} \mathrm{O} \cdot x_{i 1} \mathrm{~B}_{2} \mathrm{O}_{3} ; 298.15 \mathrm{~K}\right)=$

$=-1305.296 \cdot x\left(\mathrm{~B}_{2} \mathrm{O}_{3}\right)-738.059 \cdot x\left(\mathrm{Li}_{2} \mathrm{O}\right)-$

$-678.501 \cdot x\left(\mathrm{Na}_{2} \mathrm{O}\right)-723.862 \cdot x\left(\mathrm{~K}_{2} \mathrm{O}\right) \mathrm{kJ} \cdot \mathrm{mol}^{-1}$.

$\Delta_{f} H^{\circ}\left(x_{i j} \mathrm{Me}_{2} \mathrm{O} \cdot x_{i 1} \mathrm{GeO}_{2} ; 298.15 \mathrm{~K}\right)=$

$=-626.676 \cdot x\left(\mathrm{GeO}_{2}\right)-698.569 \cdot x\left(\mathrm{Li}_{2} \mathrm{O}\right)-$

$-579.601 \cdot x\left(\mathrm{Na}_{2} \mathrm{O}\right)-569.652 \cdot x\left(\mathrm{~K}_{2} \mathrm{O}\right) \mathrm{kJ} \cdot \mathrm{mol}^{-1}$.

The standard heat capacity equations were calculated:

$C_{p}{ }^{\circ}\left(x_{i j} \mathrm{Me}_{2} \mathrm{O} \cdot x_{i 1} \mathrm{SiO}_{2} ; 298.15 \mathrm{~K}\right)=43.657 \cdot x\left(\mathrm{SiO}_{2}\right)+$

$+57.412 \cdot x\left(\mathrm{Li}_{2} \mathrm{O}\right)+69.428 \cdot x\left(\mathrm{Na}_{2} \mathrm{O}\right)+$

$+73.374 \cdot x\left(\mathrm{~K}_{2} \mathrm{O}\right) \mathrm{J} \cdot \mathrm{K}^{-1} \cdot \mathrm{mol}^{-1}$.

$C_{p}{ }^{\circ}\left(x_{i j} \mathrm{Me}_{2} \mathrm{O} \cdot x_{i 1} \mathrm{~B}_{2} \mathrm{O}_{3} ; 298.15 \mathrm{~K}\right)=58.104 \cdot x\left(\mathrm{~B}_{2} \mathrm{O}_{3}\right)+$

$+62.917 \cdot x\left(\mathrm{Li}_{2} \mathrm{O}\right)+72.246 \cdot x\left(\mathrm{Na}_{2} \mathrm{O}\right)+$

$+75.736 \cdot x\left(\mathrm{~K}_{2} \mathrm{O}\right) \mathrm{J} \cdot \mathrm{K}^{-1} \cdot \mathrm{mol}^{-1}$.

$C_{p}{ }^{\circ}\left(x_{i j} \mathrm{Me}_{2} \mathrm{O} \cdot x_{i 1} \mathrm{GeO}_{2} ; 298.15 \mathrm{~K}\right)=51.961 \cdot x\left(\mathrm{GeO}_{2}\right)+$

$+54.455 \cdot x\left(\mathrm{Li}_{2} \mathrm{O}\right)+68.454 \cdot x\left(\mathrm{Na}_{2} \mathrm{O}\right)+$

$+76.505 \cdot x\left(\mathrm{~K}_{2} \mathrm{O}\right) \mathrm{J} \cdot \mathrm{K}^{-1} \cdot \mathrm{mol}^{-1}$

When conducting a regression analysis, the following statistics were obtained. The correlation coefficient, 
indicating the correctness of the calculation method, was > 0.99 for Eqs. (6-14). Standard error (SE) characterises the overall accuracy of the resulting equations. When estimating the entropy, the SE for silicates, borates, and germanates are $0.9 \mathrm{~J} \cdot \mathrm{K}^{-1} \cdot \mathrm{mol}^{-1}, 1.7 \mathrm{~J} \cdot \mathrm{K}^{-1} \cdot \mathrm{mol}^{-1}$ and $4 \mathrm{~J} \cdot \mathrm{K}^{-}$ ${ }^{1} \cdot \mathrm{mol}^{-1}$ respectively. When evaluating the enthalpy of formation of silicates, borates, and germanates, the corresponding SE are $0.4 \mathrm{~kJ} \cdot \mathrm{mol}^{-1}, 3 \mathrm{~kJ} \cdot \mathrm{mol}^{-1}$ and $9 \mathrm{~kJ} \cdot \mathrm{mol}$ ${ }^{1}$, while for standard heat capacity, SE for silicates, borates and germanates are $1.2 \mathrm{~J} \cdot \mathrm{K}^{-1} \cdot \mathrm{mol}^{-1}, 11 \mathrm{~J} \cdot \mathrm{K}^{-1} \cdot \mathrm{mol}^{-1}$ and 7 $\mathrm{J} \cdot \mathrm{K}^{-1} \cdot \mathrm{mol}^{-1}$ respectively. It can be seen that standard errors for silicates are less than those for borates and germanates. This is due to the fact that the well-studied compounds were included in the initial matrix of silicates with a small experimental error.

A comparison of the heat capacity [18] of pure silicon oxides $\left(44.42 \mathrm{~J} \cdot \mathrm{K}^{-1} \cdot \mathrm{mol}^{-1}\right)$, boron $\left(62.98 \mathrm{~J} \cdot \mathrm{K}^{-1} \cdot \mathrm{mol}^{-1}\right)$ and germanium $\left(51.95 \mathrm{~J} \cdot \mathrm{K}^{-1} \cdot \mathrm{mol}^{-1}\right)$ with the corresponding coefficients in equations (12-14) shows good convergence between them. The heat capacities of pure lithium $(54.25$ $\left.\mathrm{J} \cdot \mathrm{K}^{-1} \cdot \mathrm{mol}^{-1}\right)$ and sodium $\left(68.56 \mathrm{~J} \cdot \mathrm{K}^{-1} \cdot \mathrm{mol}^{-1}\right)$ oxides are also quite close to the obtained coefficients. The value of $C_{p}{ }^{\circ}(298.15 \mathrm{~K})$ for $\mathrm{K}_{2} \mathrm{O}$ equal to $84.53 \mathrm{~J} \cdot \mathrm{K}^{-1} \cdot \mathrm{mol}^{-1}$ used in the work [18] is close to the accepted value $\left(83.68 \mathrm{~J} \cdot \mathrm{K}^{-}\right.$
${ }^{1} \cdot \mathrm{mol}^{-1}$ ) in the reference book [28]. However, this value differs from the calculated values in our work. Indeed, there appears to be no experimental work on determining the heat capacity of potassium oxide; nevertheless, the empirical value $72 \mathrm{~J} \cdot \mathrm{K}^{-1} \cdot \mathrm{mol}^{-1}$ is given in the fundamental reference book [29], which is in good agreement with our data.

Table 1 presents a comparison of experimental and calculated data obtained by the NKR method and regression analysis for borates, silicates and germanates. The error in the data obtained by the regression method is less than or equal to the error in the results of NKR [18]. The especially significant difference in heat capacity values for potassium borates and silicates is associated with the slightly overestimated heat capacity value of potassium oxide used for the Neumann-Kopp rule.

Table 2 presents a comparison of experimental and calculated data obtained by the different methods for the same compounds. It can be seen that Zhuang's method [21], despite not using experimental data, provides good results. It goes without saying that the results obtained using regression are in better agreement with experimental data. For most compounds, the deviation of the calculated and experimental data is less than $1 \%$.

Table 1. Comparison of referenced and calculated data on the heat capacity of some borates, silicates and germanates.

\begin{tabular}{|c|c|c|c|c|c|}
\hline \multirow[t]{2}{*}{ Compound } & $\begin{array}{l}C_{p}{ }^{\circ}(\text { ref. data }), \\
\mathrm{J} \cdot \mathrm{K}^{-1} \cdot \mathrm{mol}^{-1}\end{array}$ & $\begin{array}{l}C_{p}{ }^{\circ}(\mathrm{NKR}), \\
\mathrm{J} \cdot \mathrm{K}^{-1} \cdot \mathrm{mol}^{-1} \\
\end{array}$ & $\Delta C_{p}^{\circ}, \%$ & $\begin{array}{l}C_{p}{ }^{\circ}(\text { regression }), \\
\mathrm{J} \cdot \mathrm{K}^{-1} \cdot \mathrm{mol}^{-1}\end{array}$ & $\Delta C_{p}{ }^{\circ}, \%$ \\
\hline & [28-30] & [18] & & \multicolumn{2}{|l|}{ This work } \\
\hline $\mathrm{K}_{2} \mathrm{~B}_{4} \mathrm{O}_{7}$ & $170.5 \pm 1.7$ & 210.49 & 23.45 & 191.94 & 12.58 \\
\hline $\mathrm{K}_{2} \mathrm{~B}_{6} \mathrm{O}_{10}$ & $261.9 \pm 2.5$ & 273.47 & 4.42 & 250.05 & -4.53 \\
\hline $\mathrm{K}_{2} \mathrm{~B}_{8} \mathrm{O}_{13}$ & $321.3 \pm 3.35$ & 336.45 & 4.72 & 308.15 & -4.09 \\
\hline $\mathrm{KBO}_{2}$ & $67 \pm 0.21$ & 73.76 & 10.09 & 66.92 & -0.12 \\
\hline $\mathrm{Li}_{2} \mathrm{~B}_{4} \mathrm{O}_{7}$ & $183 \pm 1.67$ & 180.21 & -1.52 & 179.12 & -2.12 \\
\hline $\mathrm{Li}_{2} \mathrm{~B}_{8} \mathrm{O}_{13}$ & $325.5 \pm 4.2$ & 306.17 & -5.94 & 295.33 & -9.27 \\
\hline $\mathrm{Li}_{2} \mathrm{~B}_{6} \mathrm{O}_{10}$ & $293.2 \pm 1.5$ & 243.2 & -17.05 & 237.23 & -19.09 \\
\hline $\mathrm{LiBO}_{2}$ & $60.37 \pm 0.6$ & 58.62 & -2.90 & 60.51 & 0.23 \\
\hline $\mathrm{Na}_{2} \mathrm{~B}_{4} \mathrm{O}_{7}$ & $186.77 \pm 0.63$ & 194.52 & 4.15 & 188.45 & 0.90 \\
\hline $\mathrm{Na}_{2} \mathrm{~B}_{6} \mathrm{O}_{10}$ & $243.5 \pm 2.5$ & 257.5 & 5.75 & 246.56 & 1.26 \\
\hline $\mathrm{Na}_{2} \mathrm{~B}_{8} \mathrm{O}_{13}$ & $304.89 \pm 8.4$ & 320.48 & 5.11 & 304.66 & -0.07 \\
\hline $\mathrm{NaBO}_{2}$ & $65.94 \pm 0.21$ & 65.77 & -0.26 & 65.18 & -1.16 \\
\hline $\mathrm{K}_{2} \mathrm{Si}_{2} \mathrm{O}_{5}$ & $160.95 \pm 0.44$ & 173.37 & 7.72 & 160.69 & -0.16 \\
\hline $\mathrm{K}_{2} \mathrm{Si}_{4} \mathrm{O}_{9}$ & $247.2 \pm 2$ & 262.21 & 6.07 & 248.00 & 0.32 \\
\hline $\mathrm{K}_{2} \mathrm{SiO}_{3}$ & $118.7 \pm 0.62$ & 128.95 & 8.64 & 117.03 & -1.41 \\
\hline $\mathrm{Li}_{2} \mathrm{Si}_{2} \mathrm{O}_{5}$ & $138.77 \pm 0.42$ & 143.09 & 3.11 & 144.73 & 4.29 \\
\hline $\mathrm{Li}_{2} \mathrm{SiO}_{3}$ & $100 \pm 0.29$ & 98.67 & -1.33 & 101.07 & 1.07 \\
\hline $\mathrm{Li}_{4} \mathrm{SiO}_{4}$ & $155.23 \pm 2$ & 152.92 & -1.49 & 158.48 & 2.09 \\
\hline $\mathrm{Na}_{2} \mathrm{Si}_{2} \mathrm{O}_{5}$ & $156.5 \pm 0.87$ & 157.4 & 0.58 & 156.74 & 0.15 \\
\hline $\mathrm{Na}_{2} \mathrm{SiO}_{3}$ & $111.81 \pm 0.26$ & 112.98 & 1.05 & 113.08 & 1.14 \\
\hline $\mathrm{Na}_{4} \mathrm{SiO}_{4}$ & $184.72 \pm 0.84$ & 181.54 & -1.72 & 182.51 & -1.19 \\
\hline $\mathrm{Li}_{2} \mathrm{GeO}_{3}$ & $101.8 \pm 0.42$ & 106.2 & 4.32 & 106.42 & 4.53 \\
\hline $\mathrm{Na}_{2} \mathrm{GeO}_{3}$ & $121.75 \pm 0.42$ & 120.51 & -1.02 & 120.41 & -1.10 \\
\hline $\mathrm{K}_{2} \mathrm{GeO}_{3}$ & $129.08 \pm 0.42$ & 136.48 & 5.73 & 128.47 & -0.48 \\
\hline
\end{tabular}


Table 2. Comparison of referenced and calculated data on the enthalpy of formation (298.15 K) of some borates, silicates and germanates.

\begin{tabular}{|c|c|c|c|c|c|}
\hline \multirow[t]{2}{*}{ Compound } & $\begin{array}{l}\Delta_{f} H^{\circ} \text { (ref. data), } \\
\mathrm{kJ} \cdot \mathrm{mol}^{-1}\end{array}$ & $\begin{array}{l}\Delta_{H} H^{\circ} \text { (estimation), } \\
\mathrm{kJ} \cdot \mathrm{mol}^{-1}\end{array}$ & $\Delta, \%$ & $\begin{array}{l}\Delta_{f} H^{\circ} \text { (regression), } \\
\mathrm{kJ} \cdot \mathrm{mol}^{-1}\end{array}$ & $\Delta, \%$ \\
\hline & {$[28-30]$} & \multicolumn{2}{|l|}{ [21] } & \multicolumn{2}{|l|}{ This work } \\
\hline $\mathrm{K}_{2} \mathrm{~B}_{4} \mathrm{O}_{7}$ & $-3334 \pm 6.3$ & -3290.06 & -1.32 & -3334.45 & 0.01 \\
\hline $\mathrm{K}_{2} \mathrm{~B}_{6} \mathrm{O}_{10}$ & $-4633 \pm 10.4$ & -4609.87 & -0.50 & -4639.75 & 0.15 \\
\hline $\mathrm{K}_{2} \mathrm{~B}_{8} \mathrm{O}_{13}$ & $-5945 \pm 5.9$ & -5910.53 & -0.58 & -5945.05 & 0.00 \\
\hline $\mathrm{KBO}_{2}$ & $-995 \pm 8$ & -961.184 & -3.40 & -1014.58 & 1.97 \\
\hline $\mathrm{Li}_{2} \mathrm{~B}_{4} \mathrm{O}_{7}$ & $-3362 \pm 6.3$ & -3431.74 & 2.07 & -3348.65 & -0.40 \\
\hline $\mathrm{Li}_{2} \mathrm{~B}_{8} \mathrm{O}_{13}$ & $-5914 \pm 6.8$ & -6033.44 & 2.02 & -5959.24 & 0.77 \\
\hline $\mathrm{Li}_{2} \mathrm{~B}_{6} \mathrm{O}_{10}$ & $-4660 \pm 5.6$ & -4739.82 & 1.71 & -4653.95 & -0.13 \\
\hline $\mathrm{LiBO}_{2}$ & $-1019.2 \pm 0.8$ & -1043.76 & 2.41 & -1021.68 & 0.24 \\
\hline $\mathrm{Na}_{2} \mathrm{~B}_{4} \mathrm{O}_{7}$ & $-3277 \pm 8$ & -3278.91 & 0.06 & -3289.09 & 0.37 \\
\hline $\mathrm{Na}_{2} \mathrm{~B}_{6} \mathrm{O}_{10}$ & $-4580 \pm 9.2$ & -4590.48 & 0.23 & -4594.39 & 0.31 \\
\hline $\mathrm{Na}_{2} \mathrm{~B}_{8} \mathrm{O}_{13}$ & $-5912 \pm 8$ & -5886.2 & -0.44 & -5899.69 & -0.21 \\
\hline $\mathrm{NaBO}_{2}$ & $-975.7 \pm 2.1$ & -963.857 & -1.21 & -991.899 & 1.66 \\
\hline $\mathrm{K}_{2} \mathrm{Si}_{2} \mathrm{O}_{5}$ & $-2496 \pm 18$ & -2410 & -3.45 & -2490.54 & -0.22 \\
\hline $\mathrm{K}_{2} \mathrm{Si}_{4} \mathrm{O}_{9}$ & $-4325 \pm 11$ & -4276.74 & -1.12 & -4330.11 & 0.12 \\
\hline $\mathrm{K}_{2} \mathrm{SiO}_{3}$ & $-1568 \pm 12$ & -1442.86 & -7.98 & -1570.75 & 0.18 \\
\hline $\mathrm{Li}_{2} \mathrm{Si}_{2} \mathrm{O}_{5}$ & $-2561 \pm 4$ & -2583.8 & 0.89 & -2560.28 & -0.03 \\
\hline $\mathrm{Li}_{2} \mathrm{SiO}_{3}$ & $-1630 \pm 24$ & -1632.1 & 0.13 & -1640.49 & 0.64 \\
\hline $\mathrm{Li}_{4} \mathrm{SiO}_{4}$ & $-2311.66 \pm 2.1$ & -2271.67 & -1.73 & -2361.2 & 2.14 \\
\hline $\mathrm{Na}_{2} \mathrm{Si}_{2} \mathrm{O}_{5}$ & $-2439.5 \pm 39.5$ & -2421.29 & -0.75 & -2464.96 & 1.04 \\
\hline $\mathrm{Na}_{2} \mathrm{SiO}_{3}$ & $-1544.5 \pm 23.5$ & -1465.03 & -5.15 & -1545.17 & 0.04 \\
\hline $\mathrm{Na}_{4} \mathrm{SiO}_{4}$ & $-2180 \pm 50$ & -1928.41 & -11.54 & -2170.56 & -0.43 \\
\hline $\mathrm{Li}_{2} \mathrm{GeO}_{3}$ & - & -1332.45 & - & -1325.25 & - \\
\hline $\mathrm{Na}_{2} \mathrm{GeO}_{3}$ & - & -1166.97 & - & -1206.28 & - \\
\hline $\mathrm{K}_{2} \mathrm{GeO}_{3}$ & - & -1148.3 & - & -1196.33 & - \\
\hline
\end{tabular}
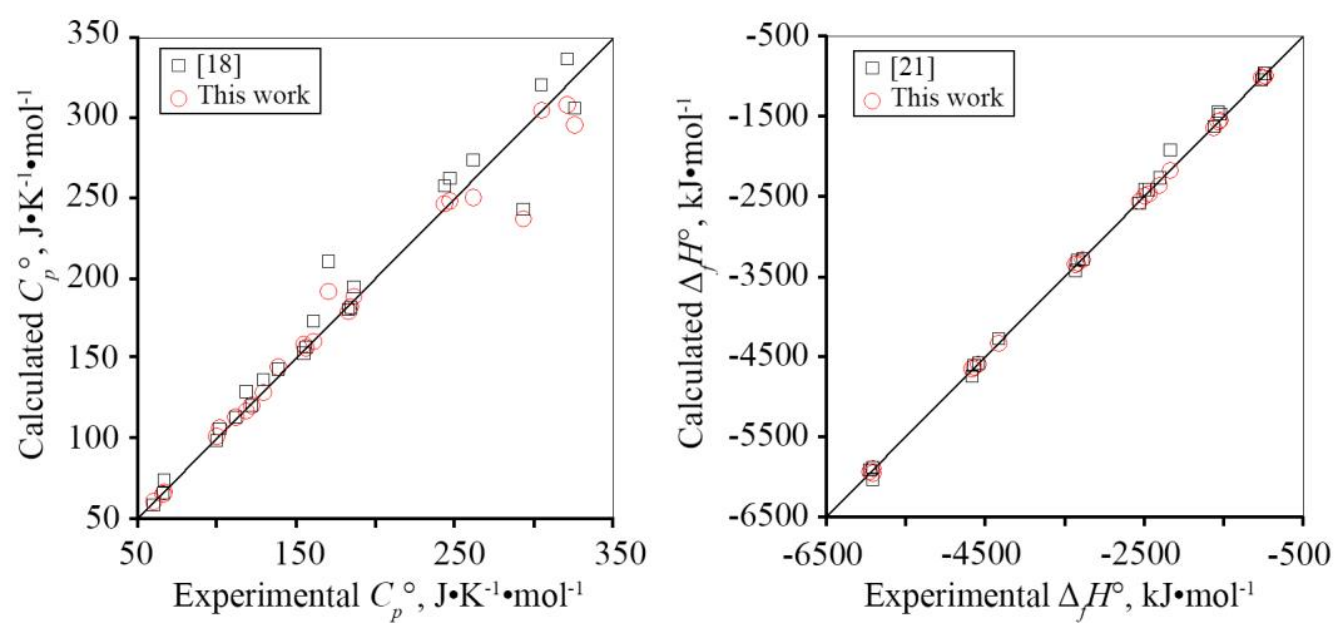

Figure 1. Comparison of calculated and experimental data for heat capacity (left) and enthalpy of formation (right) of some silicates, borates and germanates. The data are taken from Tables 1 and 2 (Figure is in color in the on-line version of the paper). 

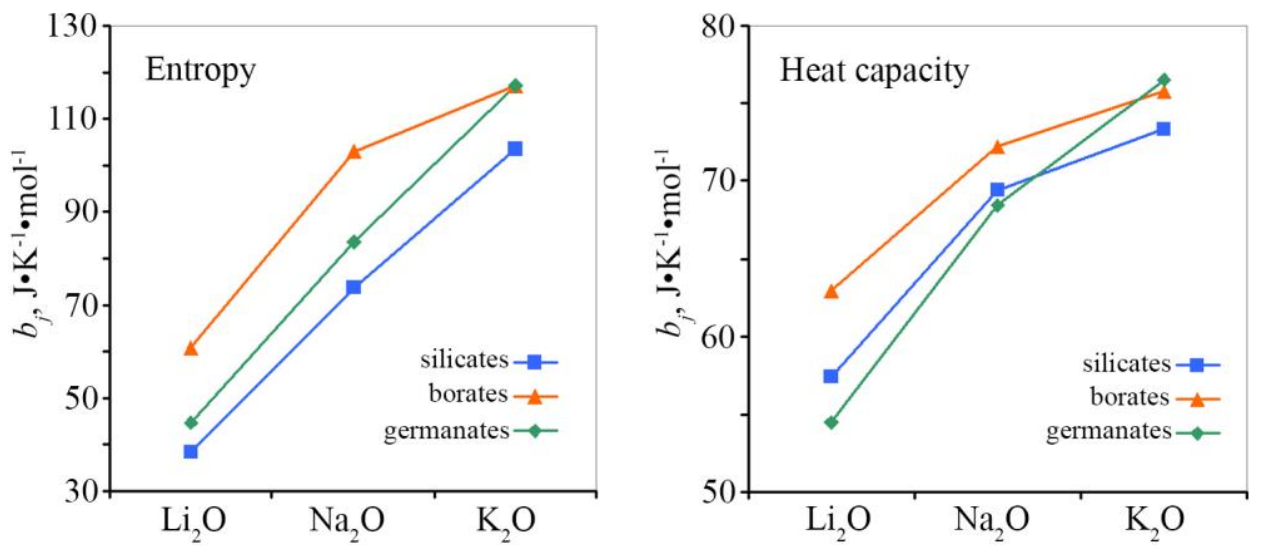

Figure 2. Values of the coefficients bj for the oxides of Li, Na and $\mathrm{K}$ in silicate, borate and germanate systems in calculating the entropy (left) and heat capacity (right) (Figure is in color in the on-line version of the paper).

A general comparison of different calculation methods with the reference data is presented in Figure 1. It can be seen that the NKR method [18] gives somewhat higher heat capacities than the experimental ones [28-30]. With the exception of a few points, regression analysis agrees much better with reference data. As can be seen in Figure 1 on the right, both methods for estimating the enthalpy of formation agree well with experimental data.

\subsection{Coefficient analysis}

An analysis of Eqs. (6-14) shows that the coefficients for the same alkali metal oxides differ for silicates, borates and germanates (Figures 2-3). It should be noted that the values of the coefficient $b_{j}$ depend not only on the type of alkali metal oxide, but also on the class of the compound. Thus, for borates, the values of $b_{j}$ for calculating entropy and heat capacity are larger than the corresponding coefficients for silicates (Figure 2). In the case of enthalpy of formation, the converse situation is observed (Figure 3 ). The dependence of the values of $b_{j}$ on the class of compound is most clearly manifested for the enthalpy of formation. Thus, for lithium oxide in silicates, borates and germanates, the values of $b_{j}$ differ by about 5 rel. $\%$, whereas for potassium oxide the difference reaches 20 rel. $\%$. It should be noted that the difference in the coefficients exceeds the standard error. Therefore, when evaluating the thermodynamic properties for ternary oxide compounds, it is necessary to take into account the difference in the values of $b_{j}$.

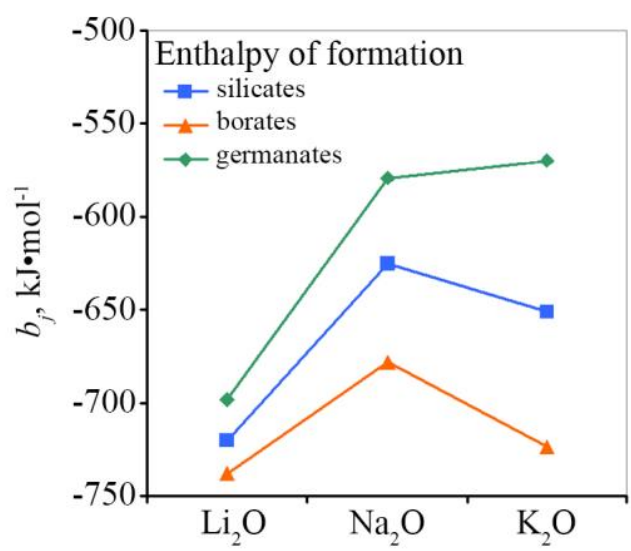

Figure 3. Values of the coefficients bj for the oxides of $\mathrm{Li}$,

$\mathrm{Na}$ and $\mathrm{K}$ in silicate, borate and germanate systems in calculating the enthalpy of formation (Figure is in color in the on-line version of the paper).

\subsection{Ternary oxide compounds}

In order to calculate the thermodynamic potentials of complex compounds such as borogermanates and germanosilicates, it is necessary to take into account the different contribution of alkali metal oxides to the total composition. It is assumed that the $\mathrm{Li}, \mathrm{Na}$, and $\mathrm{K}$ cations are uniformly distributed between the borate and germanate sublattices in the case of borogermanates, and, respectively, between the germanate and silicate sublattices in germanosilicates. The bmix coefficients for lithium, sodium and potassium oxides in borogermanates (germanosilicates) are equal to the sum of the corresponding coefficients for borates (silicates) and germanates multiplied by the fraction of the borate (silicate) and germanate component:

$$
\begin{aligned}
& b\left(\mathrm{Me}_{2} \mathrm{O}\right)_{\text {mix }}= \\
& =\frac{b\left(\mathrm{Me}_{2} \mathrm{O}\right)_{\mathrm{B}_{2} \mathrm{O}_{3}} \cdot x\left(\mathrm{~B}_{2} \mathrm{O}_{3}\right)+b\left(\mathrm{Me}_{2} \mathrm{O}\right)_{\mathrm{GeO}_{2}} \cdot x\left(\mathrm{GeO}_{2}\right)}{x\left(\mathrm{~B}_{2} \mathrm{O}_{3}\right)+x\left(\mathrm{GeO}_{2}\right)}
\end{aligned}
$$

As an example, we present a calculation of the enthalpy of formation of the $\mathrm{K}_{2} \mathrm{~B}_{2} \mathrm{Ge}_{3} \mathrm{O}_{10}$ compound, which consists of the oxides $\mathrm{K}_{2} \mathrm{O}, \mathrm{B}_{2} \mathrm{O}_{3}$ and $\mathrm{GeO}_{2}$ in a ratio of 1:1:3. In Eq. (15), we substitute the data of eq. (10-11), thus obtaining:

$$
\begin{aligned}
& b\left(\mathrm{~K}_{2} \mathrm{O}\right)_{\text {mix }}=\frac{-723.862 \cdot 1+(-569.652) \cdot 3}{1+3}= \\
& =-608.204 \mathrm{~kJ} \cdot \mathrm{mol}^{-1}
\end{aligned}
$$

$$
\begin{aligned}
& \Delta_{f} H^{\circ}\left(\mathrm{K}_{2} \mathrm{~B}_{2} \mathrm{Ge}_{3} \mathrm{O}_{10} ; 298.15 \mathrm{~K}\right)= \\
& =-608.204 \cdot 1-1305.296 \cdot 1-626.676 \cdot 3= \\
& =-3793.5 \mathrm{~kJ} \cdot \mathrm{mol}^{-1} .
\end{aligned}
$$

Using this approach, the thermodynamic properties of alkaline borogermanates and germanosilicates were calculated. Data for some of these properties are presented in Table 3. 
Table 3. Calculated values of the thermodynamic functions of alkaline borogermanates and germanosilicates in the crystalline state.

\begin{tabular}{lllll}
\hline & $S^{\circ}(298.15$ & $\Delta_{f} H^{\circ}(298.15$ & $C_{p}{ }^{\circ}(298.15$ & \multirow{2}{*}{$\Delta_{f} G^{\circ}(298.15$} \\
Compound & $\mathrm{K})$, & $\mathrm{K})$, & $\mathrm{K})$, & $\mathrm{K})$, \\
& $\mathrm{J} \cdot \mathrm{K}^{-1} \cdot \mathrm{mol}^{-1}$ & $\mathrm{~kJ} \cdot \mathrm{mol}^{-1}$ & $\mathrm{~J} \cdot \mathrm{K}^{-1} \cdot \mathrm{mol}^{-1}$ & $\mathrm{~kJ} \cdot \mathrm{mol}^{-1}$ \\
\cline { 2 - 5 } & $\mathrm{Eq} \cdot(6-8)$ & $\mathrm{Eq} \cdot(9-11)$ & $\mathrm{Eq} \cdot(12-14)$ & \\
\hline $\mathrm{Li}_{2} \mathrm{~B}_{2} \mathrm{Ge}_{3} \mathrm{O}_{10}$ & 237.9 & -3894 & 270.6 & -3610 \\
$\mathrm{Na}_{2} \mathrm{~B}_{2} \mathrm{Ge}_{3} \mathrm{O}_{10}$ & 277.6 & -3790 & 283.4 & -3505 \\
$\mathrm{~K}_{2} \mathrm{~B}_{2} \mathrm{Ge}_{3} \mathrm{O}_{10}$ & 306.4 & -3794 & 290.3 & -3509 \\
$\mathrm{Li}_{2} \mathrm{~B}_{4} \mathrm{GeO}_{9}$ & 190.6 & -3962 & 228.3 & -3710 \\
$\mathrm{Na}_{2} \mathrm{~B}_{4} \mathrm{GeO}_{9}$ & 231.7 & -3883 & 239.2 & -3630 \\
$\mathrm{~K}_{2} \mathrm{~B}_{4} \mathrm{GeO}_{9}$ & 252.4 & -3910 & 244.2 & -3655 \\
$\mathrm{~K}_{4} \mathrm{~B}_{8} \mathrm{Ge}_{2} \mathrm{O}_{18}$ & 504.8 & -7819 & 488.3 & -7310 \\
$\mathrm{Li}_{2} \mathrm{SiGe}_{3} \mathrm{O}_{9}$ & 232.2 & -3504 & 254.7 & -3247 \\
$\mathrm{Na}_{2} \mathrm{SiGe}_{3} \mathrm{O}_{9}$ & 270.1 & -3391 & 268.2 & -3132 \\
$\mathrm{~K}_{2} \mathrm{SiGe}_{3} \mathrm{O}_{9}$ & 302.9 & -3390 & 275.3 & -3133 \\
$\mathrm{Li}_{4} \mathrm{SiGe}_{2} \mathrm{O}_{8}$ & 225.5 & -3585 & 258.5 & -3349 \\
$\mathrm{Na}_{4} \mathrm{SiGe}_{2} \mathrm{O}_{8}$ & 300.9 & -3363 & 285.1 & -3123 \\
$\mathrm{~K}_{4} \mathrm{SiGe}_{2} \mathrm{O}_{8}$ & 365.7 & -3367 & 298.5 & -3130 \\
$\mathrm{Li}_{2} \mathrm{Si}_{2} \mathrm{GeO}_{7}$ & 175.4 & -3180 & 195.7 & -2980 \\
$\mathrm{Na}_{2} \mathrm{Si}_{2} \mathrm{GeO}_{7}$ & 212.0 & -3076 & 208.4 & -2874 \\
$\mathrm{~K}_{2} \mathrm{Si}_{2} \mathrm{GeO}_{7}$ & 243.0 & -3090 & 213.7 & -2889 \\
\hline
\end{tabular}

Although there are few experimental works in which the thermodynamic properties of borogermanates are determined, the data on the values of the standard formation enthalpy for $\mathrm{K}_{2} \mathrm{~B}_{2} \mathrm{Ge}_{3} \mathrm{O}_{10}$ and $\mathrm{K}_{2} \mathrm{~B}_{4} \mathrm{GeO}_{9} \cdot 2 \mathrm{H}_{2} \mathrm{O}$ are given in $[16,17]$ as $-3937.1 \pm 4.7 \mathrm{~kJ} \cdot \mathrm{mol}^{-1}$ and $-4560.8 \pm 3.4 \mathrm{~kJ} \cdot \mathrm{mol}^{-1}$. Since $\mathrm{K}_{2} \mathrm{~B}_{4} \mathrm{GeO}_{9} \cdot 2 \mathrm{H}_{2} \mathrm{O}$ is a hydrate, the Thermodynamic Difference Rule (TDR) [22-25] should be used to evaluate the enthalpy of formation of anhydrous $\mathrm{K}_{2} \mathrm{~B}_{4} \mathrm{GeO}_{9}$. These works provide coefficients for calculating the enthalpy of molecular water, on average coefficient being equal -300 $\mathrm{kJ} \cdot \mathrm{mol}^{-1}$. Using this coefficient, it is possible to calculate $\Delta_{f} H^{\circ}$ value for anhydrous borogermanate and compare it with the obtained results (Table 4). As can be seen, the deviations between the calculated and experimental values are less than $4 \%$.

Table 4. Comparison of referenced and calculated values of the enthalpy of formation for some potassium borogermanates.

\begin{tabular}{llll}
\hline \multirow{2}{*}{ Compound } & \multicolumn{2}{l}{$\Delta_{f} H^{\circ}(298.15 \mathrm{~K}), \mathrm{kJ} \cdot \mathrm{mol}^{-1}$} & \multirow{2}{*}{ Deviation, \% } \\
\cline { 2 - 3 } & Ref. value & Eq. $(9-11)$ & \\
\hline $\mathrm{K}_{2} \mathrm{~B}_{2} \mathrm{Ge}_{3} \mathrm{O}_{10}$ & $-3937.1 \pm 4.7[16]$ & -3793.5 & 3.6 \\
$\mathrm{~K}_{2} \mathrm{~B}_{4} \mathrm{GeO}_{9}$ & $-3960.8 \pm 3.4[17]$ & -3909.7 & 1.3 \\
\hline
\end{tabular}

\section{Conclusion}

A comparison of various methods for estimating the thermodynamic properties of binary oxides is carried out. It is shown that a regression analysis method that takes into account the error of the initial data has good accuracy and offers a versatile approach for determining the values of heat capacity, entropy and enthalpy of formation at $\mathrm{T}=$ $298.15 \mathrm{~K}$.

Based on the regression equations for calculating the thermodynamic properties of alkaline borates, germanates and silicates, a novel method is proposed for evaluating the thermodynamic properties of borogermanates and germanosilicates. The proposed method takes into account the different contributions of alkaline oxides depending on the ratio of borate (silicate) and germanate components. The basic thermodynamic potentials of alkaline borogermanates and germanosilicates are calculated. The obtained $\Delta_{f} H^{\circ}(298.15 \mathrm{~K})$ values are in good agreement with experimental data. Our results can be used for evaluating the thermodynamic properties of ternary oxides, as well as for optimising technological processes involved in the manufacture of ceramics and coatings.

\section{Acknowledgements}

This reported study was funded by RFBR (project number 18-05-00079) and State Contract (AAAA-A19119042590024-1).

\section{References}

[1] W. Cao, F. Huang, Z. Wang, R. Lei, Y. Tian, Y. Hua, H. Wang, J. Zhang, S. Xu, "Controllable structural tailoring for enhanced luminescence in highly $\mathrm{Er}^{3+}$ doped germanosilicate glasses", Opt. Lett., 43 (14), 3281-3284, (2018). doi: 10.1364/ol.43.003281

[2] X. Feng, F. Q. Li, A. X. Lin, X. X. Chai, F. Wang, Q. H. Zhu, Z. P. Wang, X. B. Sun, X. Sun, "Optically poled germanosilicate glass as a nonlinear material for second harmonic generation", Laser Phys., 29 (3), 036002, (2019). doi: 10.1088/1555-6611/aaf05e

[3] M. Gökçe, D. Koçyiğit, "Spectroscopic investigations of $\mathrm{Dy}^{3+}$ doped borogermanate glasses for laser and wLED applications", Opt. Mater., 89, 568-575, (2019). doi: 10.1016/j.optmat.2019.02.004

[4] F. Huang, F. E, R. Lei, Y. Li, B. Li, R. Ye, S. Xu, "Enhancing the $\mathrm{Er}^{3+}$ : Infrared and mid-infrared emission performance in germanosilicate-zinc glasses", $J$. Lumin., 213, 370-375, (2019). doi: 10.1016/j.jlumin.2019.05.050

[5] J. H. Kang, M. E. Davis, D. Xie, S. I. Zones, S. Smeets, L. B. McCusker, "Synthesis and characterization of CIT-13, a germanosilicate molecular sieve with extralarge pore openings", Chem. Mater., 28 (17), 62506259, (2016). doi: 10.1021/acs.chemmater.6b02468

[6] P. F. Kashaykin, A. L. Tomashuk, V. F. Khopin, A. N. Guryanov, S. L. Semjonov, E. M. Dianov, "New radiation colour centre in germanosilicate glass fibres", Quantum Electron., 48 (12), 1143-1146, (2018). doi: 10.1070/qel16850

[7] Z. E. Lin, J. Zhang, G. Y. Yang, "Synthesis and structure of $\mathrm{KBGe}_{2} \mathrm{O}_{6}$ : The first chiral zeotype borogermanate with 7-ring channels", Inorg. Chem., 42 (6), 1797-1799, (2003). doi: 10.1021/ic020511h

[8] C. -Y. Pan, H. -D. Mai, G. -Y. Yang, “A new zeotype borogermanate $\beta-\mathrm{K}_{2} \mathrm{~B}_{2} \mathrm{Ge}_{3} \mathrm{O}_{10}$ : synthesis, structure, property and conformational polymorphism", Microporous Mesoporous Mater., 168, 183-187, (2013). doi: 10.1016/j.micromeso.2012.09.004

[9] R. Pan, J. W. Cheng, B. F. Yang, G. Y. Yang, " $\mathrm{CsB}_{\mathrm{x}} \mathrm{Ge}_{6-\mathrm{x}} \mathrm{O}_{12} \quad(\mathrm{x}=1):$ a zeolite sodalite-type borogermanate with a high $\mathrm{Ge} / \mathrm{B}$ ratio by partial boron substitution", Inorg. Chem., 56 (5), 2371-2374, (2017). doi: 10.1021/acs.inorgchem.6b03002

[10] D. -B. Xiong, J. -T. Zhao, H. -H. Chen, X. -X. Yang, "A borogermanate with three-dimensional openframework layers", Chem. Eur. J., 13 (35), 9862-9865, (2007). doi: 10.1002/chem.200701009

[11] H. Xu, J.-g. Jiang, B. Yang, L. Zhang, M. He, P. Wu, "Post-synthesis treatment gives highly stable siliceous zeolites through the isomorphous substitution of silicon for germanium in germanosilicates", Angewandte 
Chemie International Edition, 53 (5), 1355-1359, (2014). doi: 10.1002/anie.201306527

[12] X. Xu, C. L. Hu, F. Kong, J. H. Zhang, J. G. Mao, J. Sun, " $\mathrm{Cs}_{2} \mathrm{GeB}_{4} \mathrm{O}_{9}$ : a new second-order nonlinear-optical crystal”, Inorg. Chem., 52 (10), 5831-5837, (2013). doi: 10.1021/ic302774h

[13] L. T. Denisova, N. V. Belousova, N. A. Galiakhmetova, V. M. Denisov, "High-temperature heat capacity of $\mathrm{YBiGeO}_{5}$ and $\mathrm{GdBiGeO}_{5}$ in the range 373 1000 K”, Phys. Solid State, 59 (5), 1047-1050, (2017). doi: 10.1134/s1063783417050080

[14] L. T. Denisova, L. A. Irtyugo, Y. F. Kargin, N. V. Belousova, V. V. Beletskii, V. M. Denisov, "Synthesis and high-temperature heat capacity of $\mathrm{Dy}_{2} \mathrm{Ge}_{2} \mathrm{O}_{7}$ and $\mathrm{Ho}_{2} \mathrm{Ge}_{2} \mathrm{O}_{7}$ ", Inorg. Mater., 54 (4), 361-365, (2018). doi: $10.1134 / \mathrm{s} 0020168518040039$

[15] L. T. Denisova, Y. F. Kargin, L. A. Irtyugo, N. V. Belousova, V. V. Beletskii, V. M. Denisov, "Heat capacity of $\mathrm{In}_{2} \mathrm{Ge}_{2} \mathrm{O}_{7}$ and $\mathrm{YInGe}_{2} \mathrm{O}_{7}$ from 320 to 1000 K”, Inorg. Mater., 54 (12), 1245-1249, (2018). doi: $10.1134 / \mathrm{s} 0020168518120026$

[16] N. Kong, H. -H. Zhang, J. Wang, Z. -H. Liu, "Thermochemical properties of microporous materials for two borogermanates, $\beta-\mathrm{K}_{2}\left[\mathrm{~B}_{2} \mathrm{Ge}_{3} \mathrm{O}_{10}\right]$ and $\mathrm{NH}_{4}\left[\mathrm{BGe}_{3} \mathrm{O}_{8}\right]$ ", J. Chem. Thermodyn., 92, 29-34, (2016). doi: 10.1016/j.jct.2015.08.032

[17] Y. Zhang, S. Lei, Z. -H. Liu, "Thermodynamic properties of microporous crystals for two hydrated borogermanates, $\quad \mathrm{K}_{2}\left[\mathrm{Ge}\left(\mathrm{B}_{4} \mathrm{O}_{9}\right)\right] \cdot 2 \mathrm{H}_{2} \mathrm{O}$ and $\mathrm{K}_{4}\left[\mathrm{~B}_{8} \mathrm{Ge}_{2} \mathrm{O}_{17}(\mathrm{OH})_{2}\right]$ ", J. Chem. Thermodyn., 61, 27-31, (2013). doi: 10.1016/j.jct.2013.01.027

[18] J. Leitner, P. Chuchvalec, D. Sedmidubský, A. Strejc, P. Abrman, "Estimation of heat capacities of solid mixed oxides", Thermochim. Acta, 395 (1), 27-46, (2002). doi: 10.1016/S0040-6031(02)00177-6

[19] O. N. Koroleva, M. V. Shtenberg, V. A. Bychinsky, A. A. Tupitsyn, K. V. Chudnenko, "Methods for calculating and matching thermodynamic properties of silicate and borate compounds", Bull. SUSU. Ser. Chem., 9 (1), 39-48, (2017). doi: 10.14529/chem170105

[20] M. V. Shtenberg, V. A. Bychinskii, O. N. Koroleva, N. M. Korobatova, A. A. Tupitsyn, S. V. Fomichev, V .A. Krenev, "Calculation of the formation enthalpies, standard entropies, and standard heat capacities of alkali and alkaline-earth germanates", Russ. J. Inorg. Chem., 62 (11), 1464-1468, (2017). doi: $10.1134 / \mathrm{S} 0036023617110183$

[21] W. Zhuang, J. Liang, Z. Qiao, J. Shen, Y. Shi, G. Rao, "Estimation of the standard enthalpy of formation of double oxide", J. Alloy Compd., 267 (1), 6-10, (1998). doi: 10.1016/S0925-8388(97)00570-7

[22] H. D. B. Jenkins, "Expanding thermodynamic databases using the thermodynamic difference rule (TDR). Exemplified by an application to retrieve new thermodynamic data for thorium compounds", J. Chem. Thermodyn., 144, 106052, (2020). doi: 10.1016/j.jct.2020.106052

[23] H. D. B. Jenkins, L. Glasser, "Difference rule a new thermodynamic principle: Prediction of standard thermodynamic data for inorganic solvates", J. Am. Chem. Soc., 126 (48), 15809-15817, (2004). doi: 10.1021/ja040137f

[24] H. D. B. Jenkins, L. Glasser, "Thermodynamic Difference Rules: a prescription for their application and usage to approximate thermodynamic data", $J$. Chem. Eng. Data, 55 (10), 4231-4238, (2010). doi: $10.1021 / \mathrm{je} 100383 \mathrm{t}$

[25] H. D. B. Jenkins, C. E. Housecroft, "The thermodynamics of uranium salts and their hydrates Estimating thermodynamic properties for nuclear and other actinoid materials using the Thermodynamic Difference Rule (TDR)", J. Chem. Thermodyn., 114, 116-121, (2017). doi: 10.1016/j.jct.2017.03.023

[26] G. F. Voronin, I. B. Kutsenok, "Universal method for approximating the standard thermodynamic functions of solids", J. Chem. Eng. Data, 58 (7), 2083-2094, (2013). doi: 10.1021/je400316m

[27] I. A. Uspenskaya, L. A. Kulikov, "Method for the estimation of standard entropy of crystal phases at $298.15 \mathrm{~K}$ on the limited temperature rRange of heat capacity measurements", J. Chem. Eng. Data, 60 (8), 2320-2328, (2015). doi: 10.1021/acs.jced.5b00217

[28] M. W. Chase, JANAF thermochemical tables the 4th edition. NIST Standard Reference Database 13., Washington, 1998.

[29] L. V. Gurvich, I. V. Veyts, V. A. Medvedev, et al., Thermodynamic properties of individual substances. Vol. 4, part 1, Hemisphere Publishing, New York, United States, 1989.

[30] V. S. Yungman, V. P. Glushko, Thermal constants of substances, Begell House, 1999. 